\title{
BMJ Open Gaps in understanding health and engagement with healthcare providers across common long-term conditions: a population survey of health literacy in 29473 Danish citizens
}

\author{
Karina Friis, ${ }^{1}$ Mathias Lasgaard, ${ }^{1,2}$ Richard H Osborne ${ }^{3}$ Helle T Maindal ${ }^{4}$
}

To cite: Friis $\mathrm{K}$, Lasgaard $\mathrm{M}$, Osborne RH, et al. Gaps in understanding health and engagement with healthcare providers across common long-term conditions: a population survey of health literacy in 29473 Danish citizens. BMJ Open 2016;5: e009627. doi:10.1136/ bmjopen-2015-009627

- Prepublication history for this paper is available online. To view these files please visit the journal online (http://dx.doi.org/10.1136/ bmjopen-2015-009627).

Received 4 August 2015 Revised 7 December 2015 Accepted 11 December 2015

CrossMark

For numbered affiliations see end of article.

Correspondence to Dr Helle T Maindal; htm@alm.au.dk

\section{ABSTRACT}

Objectives: To (1) quantify levels of subjective health literacy in people with long-term health conditions (diabetes, cardiovascular disease, chronic obstructive pulmonary disease, musculoskeletal disorders, cancer and mental disorders) and compare these to levels in the general population and (2) examine the association between health literacy, socioeconomic characteristics and comorbidity in each long-term condition group.

Design: Population-based survey in the Central Denmark Region ( $n=29$ 473).

Main outcome measures: Health literacy was measured using two scales from the Health Literacy Questionnaire (HLQ): (1) Ability to understand health information and (2) Ability to actively engage with healthcare providers.

Results: People with long-term conditions reported more difficulties than the general population in understanding health information and actively engaging with healthcare providers. Wide variation was found between disease groups, with people with cancer having fewer difficulties and people with mental health disorders having more difficulties in actively engaging with healthcare providers than other long-term condition groups. Having more than one long-term condition was associated with more difficulty in engaging with healthcare providers and understanding health information. People with low levels of education had lower health literacy than people with high levels of education.

Conclusions: Compared with the general population, people with long-term conditions report more difficulties in understanding health information and engaging with healthcare providers. These two dimensions are critical to the provision of patient-centred healthcare and for optimising health outcomes. More effort should be made to respond to the health literacy needs among individuals with long-term conditions, multiple comorbidities and low education levels, to improve health outcomes and to reduce social inequality in health.
Strengths and limitations of this study

- This is the first population-based study to explore the variation in health literacy between long-term conditions adjusted for socioeconomic factors and comorbidity.

- Most research on health literacy has explored reading ability and numeracy. This study reports on two health literacy dimensions that encompass higher order competencies including communication and interaction skills needed for uptake and use of health services.

- The ability and motivation to fill out a health survey can be viewed as a health literacy competency in itself; thus, many of the most vulnerable groups may have been excluded from our study.

- The population weights compensate for nonresponse and differences in selection probabilities, making our results representative.

- The study is limited by the self-reported survey, without clinical verification of health conditions.

\section{INTRODUCTION}

The ability of people to take active care of their health and navigate through increasingly complex healthcare systems is a key aspect of patient-centred healthcare. ${ }^{1}{ }^{2}$ Research into health literacy is consequently receiving growing attention from governments, researchers, clinicians and patients' associations. Health literacy brings together many concepts that relate to what people need in order to make effective decisions about health for themselves, their families and their communities. Health literacy as a concept has developed over the past decades, from covering mainly basic reading and numeracy skills to now covering much broader competences. At present, it is defined by the WHO as the "personal characteristics and social resources needed for individuals and communities to access, 
understand, appraise and use information and services to make decisions about health'. ${ }^{1}$ Health literacy includes the capacity to communicate, assert and enact these decisions.

Previous studies have shown that limited health literacy is associated with under-utilisation of preventive healthcare services, ${ }^{2}{ }^{3}$ poor physical and mental health, ${ }^{4}$ increased use of emergency services $^{25}$ and higher hospitalisation rates. ${ }^{2} 36$ These findings suggest that it is important to identify groups of people with low levels of health literacy who are at the greatest risk of poor or inequitable health outcomes.

Individuals with long-term conditions account for many hospital admissions and place a significant burden on national healthcare budgets. These patients frequently have to interact with a range of healthcare services and are encouraged to take active care of their health to avoid poor health outcomes. Healthcare providers need to be conscious of their patients' health literacy skills to ensure that health information is communicated effectively to help manage long-term conditions. Thus, identifying groups with low health literacy skills is an important step in devising effective engagement, prevention and intervention strategies. Most research on health literacy among people with long-term conditions focuses only on functional skills such as reading and understanding health information. ${ }^{7-9}$ Furthermore, most previous research has used small study populations in clinical settings and has not explored variation in health literacy across different long-term conditions. ${ }^{10-12}$

The present study aimed to extend previous research by exploring two distinct dimensions of health literacy: 'Ability to understand health information well enough to know what to do' and 'Ability to actively engage with healthcare providers'. Based on a large population-based survey, the first aim was to quantify levels of subjective health literacy in people with long-term health conditions (diabetes, cardiovascular disease, chronic obstructive pulmonary disease, musculoskeletal disorders, cancer and mental disorders) and compare these to levels in the general population. As health literacy is related to the contextual demands of individuals, such as their specific health conditions, current need for services and the complexity of these services, it was expected that people with long-term conditions report more difficulties in understanding health information and engaging with healthcare providers than the general population. The second aim was to examine the association between subjective health literacy, socioeconomic characteristics and comorbidity in each long-term condition groups. The assumption was that socioeconomic disadvantaged individuals and individuals with comorbidity report the highest difficulties in understanding health information and engaging with healthcare providers.

\section{METHODS}

\section{Study design and data collection}

The study was based on respondents from the 2013 Danish health and morbidity survey called 'How Are
You?' (respondents aged 25 years or older). Denmark has approximately 5.5 million inhabitants and is divided into five administrative regions. The present study comprises data from one of these regions-the Central Denmark Region-where approximately 22\% of the Danish population resides. The survey consisted of a county-stratified random sample of 46354 individuals and was drawn using the Danish Civil Registration System (each citizen has a unique personal identification number). People were invited to complete a postal or a web-based questionnaire. Three reminders were issued. Data were collected by the Central Denmark Region, between February and April 2013. A total of 29473 people $(63.6 \%)$ completed and returned the questionnaire.

\section{Measures of health literacy-the Health Literacy Questionnaire}

The health literacy dimensions were taken from the Health Literacy Questionnaire (HLQ), a new measure of health literacy that has been translated into many European and Asian languages. ${ }^{13}$ The HLQ was developed using a validity-driven approach ${ }^{14}$ including in-depth grounded consultations, cognitive interviews and extensive psychometric analyses, and was shown to be highly robust and reliable. ${ }^{13}$

The HLQ consists of nine scales, and two of the scales strongly reflecting distinct core competencies needed for participation in healthcare processes were selected. These scales cover a range of simple and more challenging health literacy-related tasks. ${ }^{15}$ The translation and adaption of the HLQ from English into Danish followed a standardised forward-backward translation procedure to ensure cross-cultural validity.

The first scale, 'Understand health information well enough to know what to do' ('Understanding'), consists of five items:

1. Confidently fill in medical forms in the correct way

2. Accurately follow the instructions...

3. Read and understand written health information

4. Read and understand all the information on medication labels

5. Understand what healthcare providers are asking you to do

People with a low score on this scale have problems understanding any written health information or instructions about treatments or medications and are unable to confidently fill in medical forms in the correct way. ${ }^{13}$

The second HLQ scale, 'Actively engage with healthcare providers' ('Engagement'), also consists of five items:

1. Make sure that healthcare providers understand your problems properly

${ }^{\mathrm{i}}$ As the HLQ is protected by copyright, some HLQ items are truncated. A full copy of the items is available from Deakin University: hlq@deakin.edu.au. 
2. Feel able to discuss your health concerns with a healthcare provider

3. Have good discussions about your health with doctors

4. Discuss things with healthcare providers until you understand all you need to

5. Ask healthcare providers questions to get the health information...

People with low scores on this scale are passive in their approach to healthcare, do not proactively seek information and advice and/or service options, and accept information without asking questions. Furthermore, they are unable to ask questions to obtain information or to clarify what they do not understand, and they accept what is offered without ensuring that it meets their needs. ${ }^{13}$

For each item, participants indicated their response using a Likert scale: $1=$ very difficult, $2=$ difficult, $3=$ easy and $4=$ very easy. Scale scores were used as dependent variables and were calculated for each individual as the mean of item scores for the five items, and then standardised to range between 1 and 4 , to be consistent with the response options. If one or two items were missing, the mean of the available items was used as the scale score. If responses to more than two items in a scale were missing, the scale score was regarded as missing. As a result of this, 1962 observations (6.7\%) were excluded for the 'Understanding' scale and 1925 observations $(6.5 \%)$ were excluded for the 'Engagement' scale. Cronbach's $\alpha$ coefficients indicated high internal consistency of both scales: 'Understanding' $\alpha=0.87$ and 'Engagement' $\alpha=0.91$. The two scales correlated at $r=0.76$.

\section{Measures of long-term conditions}

We examined health literacy among people with one of six long-term health conditions:

(1) diabetes, (2) cardiovascular disease (CVD) (myocardial infarction, angina pectoris and stroke), (3) chronic obstructive pulmonary disease (COPD), (4) musculoskeletal disorders (osteoarthritis, rheumatoid arthritis and osteoporosis), (5) cancer and (6) mental disorders lasting more than 6 months. The conditions were selected on the basis of being potentially fatal and/or debilitating. Respondents were asked if they currently and/or previously had any of the condition(s).

\section{Demographic and socioeconomic factors}

Demographic and socioeconomic factors included: age, sex, ethnic background, educational level and cohabitation status. Information on age, sex and ethnic background was collected from national registers, to avoid missing data. All other data were self-reported. Respondents were defined as Danish if they had Danish citizenship or if at least one of their parents was a Danish citizen. Using the education nomenclature (ISCED) from Statistics Denmark, we categorised educational level as low (1-10 years), medium (11-14 years of education) and high (>15 years). Cohabitation status related to whether an individual lived alone or with others (adults and/or children).
Ethics

The study was approved by the Danish Data Protection Agency (j. no: 2007-58-0010) and was undertaken in accordance with the Helsinki Declaration. Information about the survey was provided in writing and via the web. The participants' voluntary completion and return of the survey questionnaires constituted implied consent.

\section{Statistical analysis}

The unique personal identification number registered in the Danish Civil Registration System was used by Statistics Denmark to link respondents as well as nonrespondents to the Danish national registers. Weights were used to account for differences in selection probabilities and response rates. These weights were constructed using a model-based calibration approach based on register information from Statistics Denmark. Data were weighted to represent the population in the Central Denmark Region.

We described participant characteristics by long-term condition group. The level of perceived difficulty (difficulty level) of each task was calculated as the populationweighted proportion of respondents who perceived the task as 'difficult' or 'very difficult' with $95 \%$ CIs. We calculated the difficulty level of all tasks for the six longterm condition groups and for the general population.

Multivariate linear regression models were used to examine the association between each of the six longterm conditions and the two dimensions of health literacy. Models were adjusted for age, sex educational level, ethnic background, cohabitation status and other comorbid conditions. Multivariate linear regression models were also performed separately for each longterm condition group with the two dimensions of health literacy to examine the impact of age, sex, education, cohabitation status, ethnic background and comorbidities. Missing data did not exceed 3.2\% for any of the independent variables. Table 1 shows the number of missing data for each independent variable. Significance was set at $p<0.05$ for all tests. Statistical analyses were performed using STATA V.14.

\section{RESULTS}

Table 1 describes the sociodemographic characteristics of the population and the frequency with which the respondents reported one or more long-term conditions. Women reported a higher prevalence of musculoskeletal conditions, cancer and mental disorders, compared to men, while men reported a higher prevalence of diabetes and CVD. The mean age of people reporting CVD, COPD, cancer, diabetes and musculoskeletal disorders, varied from 62.8 years to 66.2 years; the lowest mean age was for people with mental disorders (48.3 years). In the general population, the mean age was 52.1 years. Of the general population, $18 \%$ had low levels of education compared with much higher levels in all long-term 
Table 1 Participant characteristics by long-term condition group

\begin{tabular}{|c|c|c|c|c|c|c|c|}
\hline & $\begin{array}{l}\text { Diabetes } \\
n=1819(5.9 \%) \\
n \%^{*}(\mathrm{Cl})\end{array}$ & $\begin{array}{l}\text { CVD } \\
n=1329(4.4 \%) \\
n \% \%^{*}(C I)\end{array}$ & $\begin{array}{l}\text { COPD } \\
n=1398(4.5 \%) \\
n \% \%^{*}(C I)\end{array}$ & $\begin{array}{l}\text { Musculoskeletal } \\
\text { disorders } \\
n=7927(25.0 \%) \\
n \% *(\mathrm{Cl})\end{array}$ & $\begin{array}{l}\text { Cancer } \\
n=973(3.0 \%) \\
n \% *(C l)\end{array}$ & $\begin{array}{l}\text { Mental disorders } \\
\mathrm{n}=1915(7.8 \%) \\
\mathrm{n} \%^{*}(\mathrm{Cl})\end{array}$ & $\begin{array}{l}\text { General population } \\
(n=29473) \\
n \%^{*}(\mathrm{Cl})\end{array}$ \\
\hline $\begin{array}{l}\text { Female sex } \\
\qquad(\text { missing data: } n=0,0.0 \%)\end{array}$ & $\begin{array}{l}795 \\
45.6 \text { (42.9 to } 48.3)\end{array}$ & $\begin{array}{l}540 \\
42.6 \text { (39.5 to } 45.7)\end{array}$ & $\begin{array}{l}680 \\
50.7 \text { (47.6 to } 53.7)\end{array}$ & $\begin{array}{l}4807 \\
61.0(59.8 \text { to } 62.3)\end{array}$ & $\begin{array}{l}501 \\
55.2(51,6 \text { to } 58,8)\end{array}$ & $\begin{array}{l}1200 \\
59.5(56.8 \text { to } 62.0)\end{array}$ & $\begin{array}{l}15448 \\
50.6(49.9 \text { to } 51.3)\end{array}$ \\
\hline $\begin{array}{l}\text { Mean age }(\mathrm{Cl}) \\
\quad(\text { missing data: } n=0,0.0 \%)\end{array}$ & - $63.8(63.1$ to 64.6$)$ & - $66.2(65.2$ to 67.1$)$ & - $65.8(64.9$ to 66.6$)$ & - $62.8(62.4$ to 63.2$)$ & - $64.0(62.9$ to 65.0$)$ & - $48.3(47.5$ to 49.0$)$ & $\begin{array}{l}- \\
52.1(51.9 \text { to } 52.3)\end{array}$ \\
\hline $\begin{array}{l}\text { Low level of education } \\
\text { (1-10 years) }\end{array}$ & 591 & 473 & 518 & 2192 & 240 & 455 & 5507 \\
\hline (missing data: $\mathrm{n}=929,3.2 \%$ ) & 33.2 (30.8 to 35.8$)$ & 36.1 (33.1 to 39.2 ) & 37.3 (34.4 to 40.3 ) & 28.4 (27.2 to 29.6$)$ & $23.5(20,6$ to 26,7$)$ & 23.9 (21.7 to 26.2$)$ & $18.0(17.4$ to 18.5$)$ \\
\hline $\begin{array}{l}\text { Living alone } \\
\quad \text { (missing data: } n=640,2.2 \% \text { ) }\end{array}$ & $\begin{array}{l}524 \\
38.4 \text { (35.6 to } 41.2)\end{array}$ & $\begin{array}{l}424 \\
42.6 \text { (39.4 to } 45.8)\end{array}$ & $\begin{array}{l}488 \\
45.8 \text { (42.6 to } 48.9)\end{array}$ & $\begin{array}{l}2196 \\
36.8 \text { (35.5 to } 38.1)\end{array}$ & $\begin{array}{l}241 \\
34.3(30,6 \text { to } 38,1)\end{array}$ & $\begin{array}{l}677 \\
46.1 \text { (43.5 to } 48.8)\end{array}$ & $\begin{array}{l}6657 \\
30.3 \text { (29.6 to } 30.9)\end{array}$ \\
\hline $\begin{array}{l}\text { Non-Danish background } \\
\text { (missing data: } n=0,0.0 \%)\end{array}$ & $\begin{array}{l}59 \\
5.2(3.9 \text { to } 6.8)\end{array}$ & $\begin{array}{l}87 \\
4.9(3.6 \text { to } 6.8)\end{array}$ & $\begin{array}{l}28 \\
3.0(2.0 \text { to } 4.5)\end{array}$ & $\begin{array}{l}179 \\
3.5(3.0 \text { to } 4.1)\end{array}$ & $\begin{array}{l}13 \\
1.9(1,1 \text { to } 3,4)\end{array}$ & $\begin{array}{l}144 \\
9.9(8.4 \text { to } 11.8)\end{array}$ & $\begin{array}{l}1073 \\
6.4(6.0 \text { to } 6.8)\end{array}$ \\
\hline Additional diseases & & & & & & & \\
\hline $\begin{array}{l}\text { Diabetes } \\
\text { (missing data: } n=502,1.7 \% \text { ) }\end{array}$ & - & $\begin{array}{l}230 \\
17.4(15.1 \text { to } 19.9)\end{array}$ & $\begin{array}{l}1227 \\
12.5(10.6 \text { to } 14.7)\end{array}$ & $\begin{array}{l}735 \\
9.8(9.1 \text { to } 10.6)\end{array}$ & $\begin{array}{l}94 \\
9.0(7,1 \text { to } 11,3)\end{array}$ & $\begin{array}{l}183 \\
9.3(7.9 \text { to } 11.0)\end{array}$ & $\begin{array}{l}1819 \\
5.9(5.6 \text { to } 6.2)\end{array}$ \\
\hline $\begin{array}{l}\text { CVD } \\
\text { (missing data: } n=502,1.7 \% \text { ) }\end{array}$ & $\begin{array}{l}230 \\
12.8(11.1 \text { to } 14.7)\end{array}$ & (10.6) & $\begin{array}{l}193 \\
13.8(11.8 \text { to } 16.0)\end{array}$ & $\begin{array}{l}627 \\
8.5(7.8 \text { to } 9.3)\end{array}$ & $\begin{array}{l}86 \\
8.3(6,6 \text { to } 10,5)\end{array}$ & $\begin{array}{l}140 \\
6.9(5.8 \text { to } 8.4)\end{array}$ & $\begin{array}{l}1329 \\
4.4(4.1 \text { to } 4.6)\end{array}$ \\
\hline $\begin{array}{l}\text { COPD } \\
\text { (missing data: } n=502,1.7 \%)\end{array}$ & $\begin{array}{l}171 \\
9.5(8.1 \text { to } 11.2)\end{array}$ & $\begin{array}{l}193 \\
14.3(12.2 \text { to } 16.6)\end{array}$ & (1) & $\begin{array}{l}724 \\
9.6(8.9 \text { to } 10.5)\end{array}$ & $\begin{array}{l}94 \\
10.1(8,0 \text { to } 12,6)\end{array}$ & $\begin{array}{l}173 \\
9.4(7.9 \text { to } 11.1)\end{array}$ & $\begin{array}{l}1398 \\
4.5(4.3 \text { to } 4.8)\end{array}$ \\
\hline $\begin{array}{l}\text { Musculoskeletal disorders } \\
\text { (missing data: } n=502,1.7 \% \text { ) }\end{array}$ & $\begin{array}{l}735 \\
41.4 \text { (38.8 to } 44.1)\end{array}$ & $\begin{array}{l}627 \\
48.7(45.6 \text { to } 51.9)\end{array}$ & $\begin{array}{l}724 \\
53.3(50.3 \text { to } 56.4)\end{array}$ & (1) & $\begin{array}{l}396 \\
40.6(37,0 \text { to } 44,2)\end{array}$ & $\begin{array}{l}705 \\
34.1 \text { (31.7 to } 36.6)\end{array}$ & $\begin{array}{l}7927 \\
25.0 \text { (24.4 to } 25.6)\end{array}$ \\
\hline $\begin{array}{l}\text { Cancer } \\
\quad \text { (missing data: } n=502,1.7 \%)\end{array}$ & $\begin{array}{l}94 \\
4.5(3.5 \text { to } 5.7)\end{array}$ & $\begin{array}{l}86 \\
5.6(4.4 \text { to } 7.2)\end{array}$ & $\begin{array}{l}94 \\
6.6(5.2 \text { to } 8.3)\end{array}$ & $\begin{array}{l}396 \\
4.8(4.3 \text { to } 5.4)\end{array}$ & 年, & $\begin{array}{l}68 \\
3.3(2.5 \text { to } 4.2)\end{array}$ & $\begin{array}{l}973 \\
3.0(2.7 \text { to } 3.2)\end{array}$ \\
\hline $\begin{array}{l}\text { Mental disorders } \\
\quad(\text { missing data: } n=502,1.7 \%)\end{array}$ & $\begin{array}{l}183 \\
12.3(10.5 \text { to } 14.3)\end{array}$ & $\begin{array}{l}140 \\
12.4(10.3 \text { to } 14.8)\end{array}$ & $\begin{array}{l}173 \\
16.1(13.8 \text { to } 18.8)\end{array}$ & $\begin{array}{l}705 \\
10.6(9.8 \text { to } 11.5)\end{array}$ & $\begin{array}{l}68 \\
8.6(6.6 \text { to } 11.0)\end{array}$ & ( & $\begin{array}{l}1915 \\
7.8(7.4 \text { to } 8.2)\end{array}$ \\
\hline
\end{tabular}

*All percentages are weighted based on register data to represent the population of the Central Denmark Region, 2013.

COPD, chronic obstructive pulmonary disease; CVD, cardiovascular disease. 
condition groups, ranging from $24 \%$ among those with cancer and mental disorder, up to $37 \%$ in those with COPD. There was a large variation in the proportion of individuals with a non-Danish background in each longterm condition group, ranging from $2 \%$ for cancer, up to $10 \%$ for mental disorders. Respondents reported multiple comorbidities. For example, around half of those with CVD (48.7\%) or COPD (53.3\%) also reported a musculoskeletal disorder.

Figure 1 presents the population-weighted estimates of the 10 health literacy items separately for each long-term condition group. Compared with the general population, respondents reported significantly higher levels of difficulty understanding health information and actively engaging with healthcare providers in the CVD, COPD, musculoskeletal and mental disorders groups, and in 9 out of 10 items in people with diabetes. However, people with cancer did not differ significantly from the general population on six of the items $(2 \mathrm{a}, 5 \mathrm{a}, 1 \mathrm{~b}, 2 \mathrm{~b}, 4 \mathrm{~b}, 5 \mathrm{~b})$. The perceived difficulty level of the health literacy items varied considerably between the groups. The most heterogeneous responses were seen for $1 \mathrm{~b}$, 'Make sure that

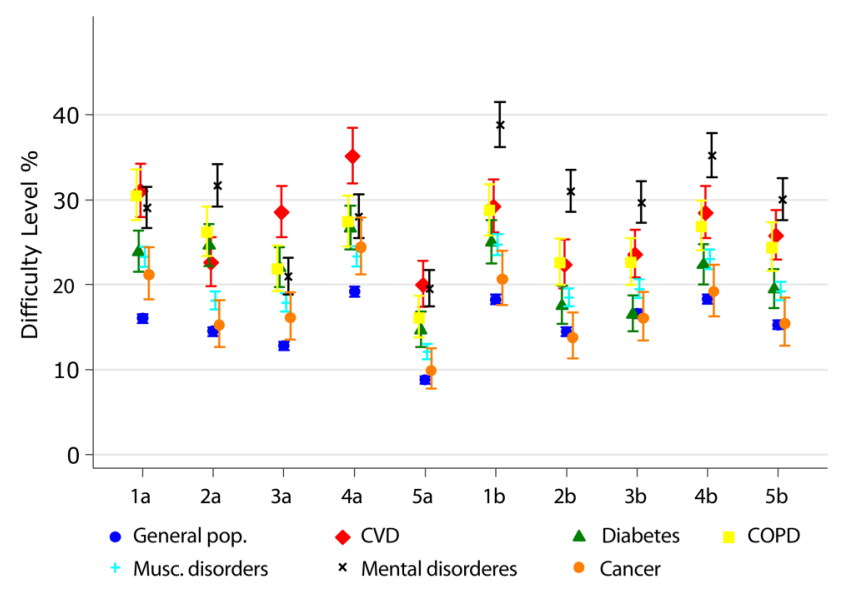

Figure 1 Population-weighted percentage ${ }^{\mathrm{a}}$ of individuals stating 'difficult' or 'very difficult' for 10 health literacy items ${ }^{b}$ by long-term condition group.

${ }^{a}$ The percentages are weighted based on register data to represent the population of the Central Denmark Region, 2013.

${ }^{\mathrm{b}} \mathbf{1 a}$. 'Confidently fill in medical forms in the correct way'; $2 \mathbf{a}$. 'Accurately follow the instructions...."; 3 a. 'Read and understand written health information'; 4a. 'Read and understand all the information on medication labels'; $5 \mathbf{a}$. 'Understand what healthcare providers are asking you to do'; 1b. 'Make sure that healthcare providers understand your problems properly'; $\mathbf{2 b}$. 'Feel able to discuss your health concerns with a healthcare provider'; $3 \mathbf{b}$. 'Have good discussions about your health with doctors'; $4 \mathbf{4 b}$. 'Discuss things with healthcare providers until you understand all you need to'; 5b. 'Ask healthcare providers questions to get the health information ${ }^{*} . .$. '.

*As the HLQ is protected by copyright, some HLQ items are truncated. A full copy of the items is available from Deakin University: hlq@deakin.edu.au healthcare providers understand your problems properly', and 2b, 'Feel able to discuss your health concerns with a healthcare provider'. People with cancer reported the lowest level of difficulty on both tasks ( $1 \mathrm{~b} 20.6 \%$ and 2b $16.1 \%$ ), whereas people with mental disorders reported the highest level of difficulty (1b $38.8 \%$ and $2 b$ $31.0 \%)$. People with mental disorders reported more difficulty in 5 of the 10 tasks than the other groups, particularly across the Engagement tasks (2a, 1b, 2b, 3b and 4b). People with CVD, COPD and mental disorders encountered more difficulty with the task described in item 1a, 'Confidently fill out medical forms in the correct way', than the other disease groups. People with CVD had the highest difficulty level on the tasks described in items 3a, 'Read and understand written health information', and 4a, 'Read and understand all the information on medication labels'.

When examining the health literacy scale scores (table 2), people from all six long-term condition groups reported higher levels of difficulty in understanding health information compared with people who did not have a long-term condition, even after adjustment for sociodemographic characteristics and other comorbidities. The same pattern was observed for the 'Ability to actively engage with healthcare providers' scale, aside from respondents reporting cancer or diabetes, who did not differ from people not having these conditions.

In all long-term condition groups, as the level of education declined, difficulties in actively engaging with healthcare providers (table 3) and understanding health information (table 4) increased. The pattern was strongly monotonic, and more pronounced across the engagement scale. People aged 65-85 years perceived fewer difficulties in engagement with healthcare providers than the younger people (25-44 years) in all disease groups except COPD. Except in those reporting CVD and cancer, being an immigrant was significantly and negatively associated with the ability to actively engage with healthcare providers; this was particularly evident among immigrants with diabetes and with COPD. Having more than one long-term condition (ie, multimorbidity) tended to be associated with lower health literacy scores as far as engaging with healthcare providers was concerned. Comorbidity with mental disorders was associated with lower health literacy among all the other disease groups, particularly in people who also had CVD, musculoskeletal disorders and cancer.

In relation to understanding health information (table 4), people with CVD and mental disorders, who were aged 85 years or older, clearly reported greater difficulties than the younger people (25-44 years). For people with diabetes, being an immigrant was strongly associated with poor ability to understand health information. People who reported CVD, cancer, or a musculoskeletal disorder in addition to reporting a mental disorder, were found to have lower ability to understand health information than those reporting only having a mental disorder. 
Table 2 Mean scale scores and association between health literacy scales and different long-term conditions

\begin{tabular}{|c|c|c|c|c|c|c|}
\hline & \multicolumn{3}{|c|}{$\begin{array}{l}\text { Understand health information well enough } \\
\text { to know what to do }\end{array}$} & \multicolumn{3}{|c|}{ Actively engage with healthcare providers } \\
\hline & $\begin{array}{l}\text { Mean scale score } \\
(95 \% \mathrm{CI})\end{array}$ & $\begin{array}{l}\text { Unadjusted } \\
\beta\end{array}$ & $\begin{array}{l}\text { Adjusted } \\
\text { B† }\end{array}$ & $\begin{array}{l}\text { Mean scale score } \\
(95 \% \mathrm{Cl})\end{array}$ & $\begin{array}{l}\text { Unadjusted } \\
\beta\end{array}$ & $\begin{array}{l}\text { Adjusted } \\
\beta \dagger\end{array}$ \\
\hline Diabetes (ref no diabetes) & $2.92(2.89$ to 2.96$)$ & $-0.18^{*}$ & $-0.09^{\star}$ & 3.00 (2.96 to 3.04$)$ & $-0.08^{\star}$ & -0.04 \\
\hline CVD (ref no CVD) & 2.83 (2.79 to 2.87$)$ & $-0.28^{*}$ & $-0.16^{\star}$ & 2.89 (2.84 to 2.93$)$ & $-0.20^{\star}$ & $-0.15^{\star}$ \\
\hline COPD (ref no COPD) & 2.89 (2.85 to 2.92$)$ & $-0.22^{*}$ & $-0.09^{*}$ & 2.91 (2.87 to 2.95$)$ & $-0.17^{\star}$ & $-0.10^{*}$ \\
\hline $\begin{array}{l}\text { Musculoskeletal disorders } \\
\text { (ref no musculoskeletal } \\
\text { disorders) }\end{array}$ & 2.99 (2.98 to 3.01$)$ & $-0.14^{*}$ & $-0.07^{\star}$ & 2.99 (2.97 to 3.00$)$ & $-0.12^{*}$ & $-0.10^{*}$ \\
\hline Cancer (ref no cancer) & 3.02 (2.97 to 3.06$)$ & $-0.08^{\star}$ & $-0.06^{\star}$ & 3.04 (3.00 to 3.09$)$ & -0.03 & 0.04 \\
\hline $\begin{array}{l}\text { Mental disorders (ref no } \\
\text { mental disorders) }\end{array}$ & $2.87(2.84$ to 2.91$)$ & $-0.24^{\star}$ & $-0.17^{\star}$ & 2.79 (2.75 to 2.83$)$ & $-0.31^{*}$ & $-0.23^{\star}$ \\
\hline
\end{tabular}

\section{DISCUSSION}

In this large population-based study, people with longterm conditions reported more difficulties than the general population in understanding health information and being able to actively engage with healthcare providers. People with mental health disorders clearly had lower levels of health literacy than other long-term condition groups. People with CVD had the most difficulty reading and understanding written health information, including medication labels. Remarkably, for most tasks, people who reported having cancer did not differ from the general population. However, in all analyses, including individuals with cancer, people with low levels of education had lower health literacy than people with high levels of education. Having more than one longterm condition was associated with more difficulty in

Table 3 Association between 'Ability to actively engage with healthcare providers' and socioeconomic characteristics and the presence of additional conditions in different long-term condition groups

\begin{tabular}{|c|c|c|c|c|c|c|}
\hline & $\begin{array}{l}\text { Diabetes } \\
(n=1819) \\
\beta\end{array}$ & $\begin{array}{l}\text { CVD } \\
(n=1329) \\
\beta\end{array}$ & $\begin{array}{l}\text { COPD } \\
(n=1398) \\
\beta\end{array}$ & $\begin{array}{l}\text { Musculoskeletal } \\
\text { disorders }(n=7927) \\
\beta\end{array}$ & $\begin{array}{l}\text { Cancer } \\
(\mathrm{n}=973) \\
\beta\end{array}$ & $\begin{array}{l}\text { Mental disorders } \\
(n=1915) \\
\beta\end{array}$ \\
\hline \multicolumn{7}{|l|}{ Gender (ref Female) } \\
\hline Male & 0.01 & $0.09^{*}$ & 0.00 & $0.05^{\star}$ & 0.03 & 0.02 \\
\hline \multicolumn{7}{|l|}{ Age (ref 25-44) } \\
\hline $45-64$ & $0.16^{*}$ & 0.08 & 0.01 & $0.07^{*}$ & $0.18^{*}$ & $0.08^{*}$ \\
\hline $65-84$ & $0.21^{*}$ & $0.18^{*}$ & 0.12 & $0.20^{\star}$ & $0.25^{*}$ & $0.16^{*}$ \\
\hline$\geq 85$ & 0.00 & -0.08 & 0.01 & 0.00 & $0.26^{*}$ & -0.03 \\
\hline \multicolumn{7}{|l|}{ Ethnic background (ref Danish) } \\
\hline Immigrant & $-0.37^{*}$ & -0.16 & $-0.48^{*}$ & $-0.12^{*}$ & -0.19 & $-0.13^{\star}$ \\
\hline \multicolumn{7}{|l|}{ Living situation (ref With others) } \\
\hline Alone & -0.05 & -0.09 & -0.07 & -0.03 & $-0.20^{*}$ & -0.03 \\
\hline \multicolumn{7}{|l|}{ Education level (ref High) } \\
\hline Medium & $-0.15^{\star}$ & -0.10 & $-0.17^{*}$ & $-0.11^{*}$ & $-0.16^{\star}$ & $-0.09^{*}$ \\
\hline Low & $-0.28^{*}$ & $-0.26^{\star}$ & $-0.23^{*}$ & $-0.24^{\star}$ & $-0.26^{\star}$ & $-0.27^{\star}$ \\
\hline \multicolumn{7}{|l|}{ Additional condition } \\
\hline Diabetes (ref no diabetes) & - & -0.02 & 0.04 & -0.00 & 0.07 & -0.04 \\
\hline CVD (ref no CVD) & $-0.14^{*}$ & - & $-0.18^{*}$ & $-0.18^{*}$ & -0.13 & $-0.25^{\star}$ \\
\hline COPD (ref no COPD) & -0.06 & -0.12 & - & $-0.11^{*}$ & 0.05 & -0.04 \\
\hline $\begin{array}{l}\text { Musculoskeletal disorders (ref } \\
\text { no musculoskeletal disorders) }\end{array}$ & -0.06 & $-0.12^{*}$ & $-0.14^{*}$ & - & -0.02 & $-0.12^{\star}$ \\
\hline Cancer (ref no cancer) & 0.05 & -0.01 & 0.09 & 0.02 & - & -0.12 \\
\hline $\begin{array}{l}\text { Mental disorders (ref no mental } \\
\text { disorders) }\end{array}$ & $-0.17^{\star}$ & $-0.34^{*}$ & $-0.19^{\star}$ & $-0.25^{\star}$ & $-0.33^{\star}$ & - \\
\hline
\end{tabular}


Table 4 Association between 'Ability to understand health information' and socioeconomic characteristics, and the presence of additional conditions in different long-term condition groups

\begin{tabular}{|c|c|c|c|c|c|c|}
\hline & $\begin{array}{l}\text { Diabetes } \\
(n=1819) \\
\beta\end{array}$ & $\begin{array}{l}\text { CVD } \\
(n=1329) \\
\beta\end{array}$ & $\begin{array}{l}\text { COPD } \\
(n=1398) \\
\beta\end{array}$ & $\begin{array}{l}\text { Musculoskeletal } \\
\text { disorders }(n=7927) \\
\beta\end{array}$ & $\begin{array}{l}\text { Cancer } \\
(\mathrm{n}=973) \\
\beta\end{array}$ & $\begin{array}{l}\text { Mental disorders } \\
(n=1915) \\
\beta\end{array}$ \\
\hline \multicolumn{7}{|l|}{ Gender (ref Female) } \\
\hline Male & -0.03 & 0.04 & -0.05 & -0.02 & -0.06 & -0.02 \\
\hline \multicolumn{7}{|l|}{ Age (ref. 25-44) } \\
\hline $45-64$ & 0.11 & 0.02 & -0.01 & 0.04 & 0.09 & 0.02 \\
\hline $65-84$ & 0.14 & 0.02 & 0.05 & $0.08^{*}$ & 0.09 & -0.05 \\
\hline$\geq 85$ & -0.14 & $-0.31^{*}$ & -0.06 & $-0.17^{*}$ & 0.03 & $-0.30^{*}$ \\
\hline \multicolumn{7}{|l|}{ Ethnic background (ref Danish) } \\
\hline Immigrant & $-0.36^{*}$ & -0.16 & -0.20 & $-0.18^{\star}$ & -0.19 & $-0.15^{\star}$ \\
\hline \multicolumn{7}{|l|}{ Living situation (ref live with others) } \\
\hline Alone & $-0.08^{*}$ & $-0.11^{*}$ & -0.07 & -0.03 & $-0.14^{*}$ & -0.01 \\
\hline \multicolumn{7}{|l|}{ Education level (ref High) } \\
\hline Medium & $-0.20^{*}$ & $-0.21^{*}$ & $-0.23^{*}$ & $-0.19^{\star}$ & $-0.27^{\star}$ & $-0.22^{*}$ \\
\hline Low & $-0.45^{\star}$ & $-0.48^{\star}$ & $-0.37^{\star}$ & $-0.39^{\star}$ & $-0.44^{\star}$ & $-0.49^{\star}$ \\
\hline \multicolumn{7}{|l|}{ Additional diseases } \\
\hline Diabetes (ref no diabetes) & - & -0.08 & -0.08 & $-0.07^{\star}$ & 0.05 & 0.02 \\
\hline CVD (ref no CVD) & $-0.16^{\star}$ & - & $-0.18^{\star}$ & $-0.15^{\star}$ & -0.12 & $-0.26^{*}$ \\
\hline COPD (ref no COPD) & -0.09 & -0.08 & - & $-0.09^{*}$ & -0.01 & 0.02 \\
\hline $\begin{array}{l}\text { Musculoskeletal disorders } \\
\text { (ref no musculoskeletal disorders) }\end{array}$ & -0.05 & -0.01 & $-0.08^{\star}$ & - & -0.02 & $-0.09^{*}$ \\
\hline Cancer (ref no cancer) & 0.06 & -0.02 & 0.00 & -0.02 & - & -0.13 \\
\hline $\begin{array}{l}\text { Mental disorders (ref no mental } \\
\text { disorders) }\end{array}$ & -0.07 & $-0.30^{\star}$ & -0.09 & $-0.21^{*}$ & $-0.27^{\star}$ & - \\
\hline
\end{tabular}

engaging with healthcare providers and understanding health information. For people with diabetes, mental disorders and musculoskeletal disorders, not being Danish was associated with lower health literacy scores. In some of the disease groups (especially in people with cancer), living alone was also associated with lower scores. Differences in these two key aspects of health literacy may well be mechanisms that lead to substantial health inequalities observed in the Danish population. These findings provide insight into possible interventions to improve health outcomes and reduce health inequalities. ${ }^{16} 17$

\section{Strengths and weaknesses of this study}

To our knowledge, this is the first population-based health literacy profile in individuals with long-term conditions. We achieved a high response rate $(64 \%)$ for a health survey. The study explores variation in health literacy between long-term conditions adjusted for a variety of different socioeconomic factors and comorbidity. Importantly, the population weights compensate for non-response and differences in selection probabilities, making our results representative.

To date, most research on health literacy has been focused on a one-dimensional concept of health literacy focused on reading ability and numeracy. ${ }^{18-20}$ We used two validated health literacy dimensions that encompass higher order competencies including communication and interaction skills needed for uptake and use of health services. However, using a self-assessed measure of health literacy causes the potential bias that people may be unaware of their lack of ability due to not knowing the demands of their disease, or they may overestimate their abilities due to perceived social desirability. Future research could be strengthened to some extent through inclusion of objective measures of individuals' ability to read health-related materials as well as formal review of the written health information they have access to. However, this would solely address parts of health literacy and have some major limitations, as direct assessments of health literacy typically employ tests of reading and comprehension. Many individuals who struggle to read tend to find such tests stressful and potentially stigmatising and a result of this would probably be more expensive population surveys with lower response rates. Another way to measure and validate the actually health literacy levels would be to combine, for example, patients' perception of levels of health literacy with the perceptions of healthcare providers or other key persons, as well as using more qualitative approaches to take other contextual factors into consideration.

The cross-sectional study design limits causal conclusions. Health literacy is a dynamic state related to an individual's abilities and the complexity of their healthcare needs. In other words, the way individuals respond to the HLQ items about their ability to understand 
health information and to actively engage with healthcare providers may vary depending on the contextual demands of their specific health conditions, their disease history, their current need for services, the availability and complexity of these services and illness trajectory. ${ }^{21}$ Those not reporting a long-term condition (the general population) may have few experiences with healthcare and/or minimal demands to manage their health, and therefore they report the least difficulty. Longitudinal studies are required to fully understand the pathways between health literacy skills and long-term conditions.

The study is somewhat limited by the self-reported survey, without clinical verification of health conditions. Therefore, we were not able to distinguish between different diagnoses and the severity of these disorders.

Furthermore, the ability and motivation to fill out a health survey can be viewed as a health literacy competency in itself; thus, many of the most vulnerable groups may have been excluded from our study. Also, as the questionnaire was not translated into other languages, people who had limited Danish language skills may not have participated in the survey. The study is therefore likely to underestimate the health literacy challenges of the Danish population.

\section{Possible explanations and implications for clinicians}

It is concerning that a high proportion of people with long-term conditions report difficulties related to understanding health information and actively engaging with healthcare providers. These results may reflect the complexity of health information and medical treatments available to patients, alongside the limited resources available to administer them. They may also reflect the fact that healthcare communication is often not tailored to meet healthcare consumers' needs. The findings from this study suggest that more effort should be made to increase health literacy among individuals with longterm conditions and multiple comorbidities, those of a non-Danish background and among those with low education levels, to improve health outcomes. Our results challenge health service providers and policymakers for service provision reform to ensure equity as the current system clearly favours individuals with higher health literacy, and also those from higher socioeconomic backgrounds. ${ }^{22}$

People with mental disorders find it more difficult to engage actively with healthcare providers than people with other long-term conditions. This may be due to the association between some mental disorders (eg, schizophrenia and depression), and cognitive and social skill deficits ${ }^{23}{ }^{24}$ Furthermore, people with mental disorders often have complex healthcare problems, which makes it more difficult for them to engage with healthcare providers in general. ${ }^{25} 26$ This calls for a re-design of health services offered to this group. The recent Scottish Government health literacy policy, 'Making it Easy', ${ }^{27}$ may inspire widespread improvements in services. The finding that people with CVD have relatively low health literacy scores compared with other disease groups may be due to the complex treatment regimens they may endure over long periods. The need for a high level of self-management may be a challenge for this target group. Individuals with cancer have higher health literacy levels than people with other long-term conditions. They also report levels of health literacy similar to the general population. Cancer is often treated by healthcare providers in secondary healthcare, so people with cancer rely less on self-care than people with CVD, for example. Cancer information and support programmes are most often routinely provided across Danish healthcare sectors, and communication appears to be more streamlined and service provision is better organised (ie, more health literacy responsive) than the care available for people with other long-term conditions.

The association between low health literacy scores and comorbidity may be linked to comorbidity being an indicator of disease severity and/or a complex diagnostic scenario that makes conversation with healthcare professionals more challenging. Furthermore, care for people with comorbidities is often more complex and timeconsuming than care for people with single diseases, and therefore requires the attention of multiple healthcare providers or facilities. ${ }^{28}$

Previous studies have shown that older age is associated with lower health literacy. ${ }^{29}{ }^{30}$ However, the present study showed that people aged 45-65 years with diabetes, musculoskeletal disorders, cancer, CVD and mental disorders, reported fewer difficulties in engaging with healthcare providers than 25-45-year-olds did. In Denmark, all citizens are affiliated with a general practitioner in their local area, ${ }^{31}$ and given that middle-aged individuals are often more experienced in navigating the healthcare system than the younger generations, this may have strengthened the capabilities of the 4565-year-olds when engaging with healthcare providers. People with CVD, musculoskeletal disorders and mental disorders in the 85-year+old age group had significantly lower scores for 'Understanding health information', which indicates that functional health literacy appears to decrease with increasing age.

The association between health literacy and low education level, having a non-Danish background and living alone, has previously been observed. ${ }^{9}{ }^{29}{ }^{32-34}$ Denmark is a country with a universal healthcare system financed primarily through income taxes, and Danish citizens are eligible to receive free medical treatment. For many years, the Danish healthcare system has sought to reduce health inequalities through prevention and health promotion directed towards vulnerable groups, in particular through measures that increase individual welfare, reduce healthcare costs and increase the work force. ${ }^{22}$ However, the social gradient in health literacy abilities shown in the present study demonstrates the urgency of renewed focus on this issue in healthcare planning. 
Health literacy is a multidimensional concept. ${ }^{1}$ Consequently, to get the full picture of the health literacy needs of a population, other dimensions of health literacy, such as those from the HLQ ${ }^{13}$ would provide even more information on what is required to improve services. The other seven HLQ health literacy indicators are important and future studies will benefit from using these to capture the full range of health consumers' needs. Furthermore, the other seven health literacy indicators would contribute with much finer details on mechanisms that are limiting the participation of some members of the community in health programmes, and leading to suboptimal health outcomes and health inequalities.

\section{CONCLUSIONS}

Compared to the general population, people with longterm conditions report more difficulties in understanding health information and engaging with healthcare providers. The result calls for greater awareness of health literacy in people with long-term conditions as these two dimensions are critical to the provision of patient-centred healthcare and for optimising health outcomes. The clear social gradient observed in our study reveals a need for a reorientation of healthcare services provision to engage and communicate with vulnerable groups in our communities in order to reduce social inequality in health.

\section{Author affiliations \\ ${ }^{1}$ Public Health and Quality Improvement, Central Denmark Region, Aarhus, Denmark \\ 2Department of Psychology, University of Southern Denmark, Odense, Denmark \\ ${ }^{3}$ Public Health Innovation, Population Health Strategic Research Centre, School of Health and Social Development, Deakin University, Geelong, Victoria, Australia \\ ${ }^{4}$ Department of Public Health, Section for Health Promotion and Health Services, Aarhus University, Aarhus, Denmark}

Twitter Follow Richard Osborne at @richardosborne4

Contributors KF, HTM, ML and RHO conceived the study questions and participated in the study design. Data analyses were performed by KF, who also wrote the first draft. All the authors participated in interpretation of the results, and contributed to the final writing of the paper. All the authors critically revised the manuscript and approved the final version.

Funding All the authors have completed the ICMJE uniform disclosure at http://www.icmje.org/coi_disclosure.pdf and declare: This study was supported by a grant from the Central Denmark Region and the 19 municipalities in the Central Denmark Region. RHO is funded in part through the National Health and Medical Research Council of Australia Senior Research Fellowship \#APP1059122; there have been no financial relationships with any organisations that might have an interest in the submitted work in the previous 3 years; and no other relationships or activities that could appear to have influenced the submitted work.

Competing interests None declared.

Ethics approval Danish Data Protection Agency.

Provenance and peer review Not commissioned; externally peer reviewed.

Data sharing statement No additional data are available.
Open Access This is an Open Access article distributed in accordance with the Creative Commons Attribution Non Commercial (CC BY-NC 4.0) license, which permits others to distribute, remix, adapt, build upon this work noncommercially, and license their derivative works on different terms, provided the original work is properly cited and the use is non-commercial. See: http:// creativecommons.org/licenses/by-nc/4.0/

\section{REFERENCES}

1. Dodson S, Good S, Osborne R. Health literacy toolkit for low and middle-income countries: a series of information sheets to empower communities and strengthen health systems. New Delhi: World Health Organization, Regional Office for South-East Asia, 2015.

2. Berkman ND, Sheridan SL, Donahue KE, et al. Health literacy interventions and outcomes: an updated systematic review. Evid Rep Technol Assess (Full Rep) 2011;199:1-941.

3. Dewalt DA, Berkman ND, Sheridan S, et al. Literacy and health outcomes: a systematic review of the literature. J Gen Intern Med 2004;19:1228-39.

4. Wolf MS, Feinglass J, Thompson J, et al. In search of 'low health literacy': threshold vs. gradient effect of literacy on health status and mortality. Soc Sci Med 2010;70:1335-41.

5. Herndon JB, Chaney M, Carden D. Health literacy and emergency department outcomes: a systematic review. Ann Emerg Med 2011;57:334-45

6. Koay K, Schofield P, Jefford M. Importance of health literacy in oncology. Asia Pac J Clin Oncol 2012;8:14-23.

7. Ishikawa $\mathrm{H}$, Yano $\mathrm{E}$. Patient health literacy and participation in the health-care process. Health Expect 2008;11:113-22.

8. Jordan JE, Osborne RH, Buchbinder R. Critical appraisal of health literacy indices revealed variable underlying constructs, narrow content and psychometric weaknesses. J Clin Epidemiol 2011;64:366-79.

9. Kickbusch I, Pelikan JM, Apfel F, et al. Health literacy the solid facts. World Health Organization, Regional Office for Europe, 2013.

10. Bains SS, Egede LE. Associations between health literacy, diabetes knowledge, self-care behaviors, and glycemic control in a low income population with type 2 diabetes. Diabetes Technol Ther 2011;13:335-41.

11. Fransen MP, von Wagner C, Essink-Bot ML. Diabetes self-management in patients with low health literacy: ordering findings from literature in a health literacy framework. Patient Educ Couns 2012:88:44-53.

12. Schillinger D, Grumbach $\mathrm{K}$, Piette J, et al. Association of health literacy with diabetes outcomes. JAMA 2002; 288:475-82.

13. Osborne $\mathrm{RH}$, Batterham RW, Elsworth GR, et al. The grounded psychometric development and initial validation of the Health Literacy Questionnaire (HLQ). BMC Public Health 2013;13:658.

14. Buchbinder R, Batterham R, Elsworth $\mathrm{G}$, et al. A validity-driven approach to the understanding of the personal and societal burden of low back pain: development of a conceptual and measurement model. Arthritis Res Ther 2011;13:R152.

15. Beauchamp A, Buchbinder R, Dodson S, et al. Distribution of health literacy strengths and weaknesses across socio-demographic groups: a cross-sectional survey using the Health Literacy Questionnaire (HLQ). BMC Public Health 2015; 15:678.

16. Starfield B, Gérvas J, Mangin D. Clinical care and health disparities Annu Rev Public Health 2012;33:89-106.

17. Greenhalgh T. Health literacy: towards system level solutions. BM 2015;350:h1026.

18. Davis TC, Long SW, Jackson $\mathrm{RH}$, et al. Rapid estimate of adult literacy in medicine: a shortened screening instrument. Fam Med 1993;25:391-5

19. Parker RM, Baker DW, Williams MV, et al. The test of functional health literacy in adults. J Gen Intern Med 1995;10:537-41.

20. Weiss BD, Mays MZ, Martz W, et al. Quick assessment of literacy in primary care: the newest vital sign. Ann Fam Med 2005;3: 514-22.

21. Edwards M, Wood F, Davies M, et al. The development of health literacy in patients with a long-term health condition: the health literacy pathway model. BMC Public Health 2012;12:130.

22. Diderichsen F, Andersen I, Manuel C, et al. Health inequalitydeterminants and policies. Scand J Public Health 2012;40(8 Suppl):12-105.

23. Galletly C. Recent advances in treating cognitive impairment in schizophrenia. Psychopharmacology (Berl) 2009;202:259-73. 
24. Godard J, Grondin S, Baruch P, et al. Psychosocial and neurocognitive profiles in depressed patients with major depressive disorder and bipolar disorder. Psychiatry Res 2011;190: 244-52.

25. Druss BG, Zhao L, Von Esenwein S, et al. Understanding excess mortality in persons with mental illness: 17-year follow up of a nationally representative US survey. Med Care 2011;49: 599-604.

26. Kilbourne AM, Morden NE, Austin K, et al. Excess heart-disease-related mortality in a national study of patients with mental disorders: identifying modifiable risk factors. Gen Hosp Psychiatry 2009;31:555-63.

27. NHS Scotland. Making it easy-A health literacy action plan for Scotland. NHS Scotland, 2015.

28. Mercer SW, Gunn J, Bower $\mathrm{P}$, et al. Managing patients with mental and physical multimorbidity. BMJ 2012;345:e5559.

29. Barber MN, Staples M, Osborne RH, et al. Up to a quarter of the Australian population may have suboptimal health literacy depending upon the measurement tool: results from a population-based survey. Health Promot Int 2009;24:252-61.

30. HLS-EU CONSORTIUM (2012). Comparative Report on Health Literacy in Eight EU Member States. The European Health Literacy Survey HLS-EU, 2012.

31. Thomson S, ORSDJM. International profiles of health care systems. The Commonwealth Fund, 2013.

32. Bo A, Friis K, Osborne $\mathrm{RH}$, et al. National indicators of health literacy: ability to understand health information and to engage actively with healthcare providers - a population-based survey among Danish adults. BMC Public Health 2014;14:1095.

33. Paasche-Orlow MK, Parker RM, Gazmararian JA, et al. The prevalence of limited health literacy. $J$ Gen Intern Med 2005;20:175-84.

34. Sørensen K, Van den Broucke S, Fullam J, et al., (HLS-EU) Consortium Health Literacy Project European. Health literacy and public health: a systematic review and integration of definitions and models. BMC Public Health 2012;12:80. 